\title{
High-performance Liquid Chromatographic Measurement of Tryptophan in Blood, Tissues, Urine, and Foodstuffs with Electrochemical and Fluorometric Detections
}

\author{
Katsumi Shibata, Michiko Onodera and Shigeo Ainara* \\ Department of Food Science and Nutrition, Teikoku Women's University, \\ Moriguchi, Osaka 570, Japan \\ * Research Institute for Food Science, Kyoto University, \\ Uji, Kyoto 611, Japan \\ Received October 29, 1990
}

\begin{abstract}
A rapid and convenient measurement of tryptophan in whole blood, serum, liver, brain, urine, and alkaline hydrolysates of proteins and foodstuff was done by high-performance liquid chromatography. The sample preparation was simply homogenized or mixed in a $5 \%$ trichloroacetic acid solution and a sample of the supernatant was injected onto a column after filtration with a $0.45-\mu \mathrm{m}$ filter. The method used a Chemcosorb 5-ODS-H column (particle size, $5 \mu \mathrm{m}, 150 \times 4.6 \mathrm{~mm}$ i.d.) eluted with $20 \mathrm{~mm}$ potassium dihydrogen phosphate ( $\mathrm{pH}$ adjusted to 3.7 by the addition of phosphoric acid) containing $1 \mathrm{~g} / \mathrm{l}$ of sodium heptane sulfonate and $3 \mathrm{mg} / \mathrm{l} \mathrm{EDTA} \cdot 2 \mathrm{Na}$-acetonitrile $(93: 7, \mathrm{v} / \mathrm{v})$ at a flow rate of $1.5 \mathrm{ml} / \mathrm{min}$. The tryptophan contents in whole blood, serum, liver, and brain were electrochemically estimated at $+1000 \mathrm{mV} v$ s. $\mathrm{Ag} / \mathrm{AgCl}$, the detection limit being $0.2 \mathrm{pmol}$ $(40.84 \mathrm{pg})$ at a signal-to-noise ratio of $5: 1$. The tryptophan contents in urine, proteins, and foodstuff were fluorometrically estimated with an excitation wavelength of $280 \mathrm{~nm}$ and with an emission wavelength of $340 \mathrm{~nm}$, the detection limit being $20 \mathrm{pmol}(4.08 \mathrm{ng})$ at a signal-to-noise ratio of $5: 1$. Tryptophan was eluted at about $10.5 \mathrm{~min}$. The total analysis time was about $12 \mathrm{~min}$.
\end{abstract}

Tryptophan is an essential amino acid and also the precursor of the neurotransmitter serotonin, behavior-active trace amines like tryptamine, and a vitamin, nicotinic acid and nicotinamide. Numerous methods have been developed for the separation and measurement of tryptophan and its metabolites. Among these methods, high-performance liquid chromatography (HPLC) has become one of the most convenient methods for the measurement of tryptophan and its metabolites. However, for the measurement of only tryptophan, some of these methods are complicated and timeconsuming ${ }^{1-5)}$ and some of these methods are applicable to only one of these biological materials such as brain, ${ }^{3,6,7)}$ plasma and serum, ${ }^{5,8-12)}$ urine, ${ }^{1,4,13)}$ or foodstuff. ${ }^{14,15)}$ That is, no HPLC method for the measurement of tryptophan in biological materials such as blood, urine, tissues and foodstuff appeared to be entirely adequate. We report an isocratic reversed-phase ion-pair HPLC method using electrochemical and fluorometric detections that permits the measurement of tryptophan in biological materials and foodstuff in less than $12 \mathrm{~min}$. The sample preparation was simply homogenized or mixed in a $5 \%$ trichloroacetic acid solution and a sample of the supernatant was injected onto the column after filtration with a $0.45-\mu \mathrm{m}$ filter.

\section{Materials and Methods}

Chemicals. Tryptophan was obtained from Wako Pure Chemical Co., (Osaka, Japan). Sodium heptane sulfonate was purchased from Tokyo Kasei Kogyo Co. (Tokyo, Japan). Lysozyme (chicken egg white, Grade I) and albumin (chicken, Fraction V) were obtained from Sigma Chemical Co. (St. Louis, MO, U.S.A.). Wheat flour (hard wheat bread flours) was obtained from Nisshin Flour Milling Co (Tokyo, Japan). All the other chemicals used were of the highest commercial grade available. The concentration of tryptophan in water was calculated using the value for the molar absorptivity of $4930 \mathrm{M}^{-1} \cdot \mathrm{cm}^{-1}$. 
Analysis. The apparatus consisted of an LC 4-A liquid chromatograph with an Irica E-502 electrochemical detector with a glassy carbon electrode (Irica, Kyoto, Japan) and a RF-540 spectrofluorophotometer equipped with an LC-flow-cell unit (Shimadzu, Kyoto, Japan), a Model 7125 syringe loading sample injector (Rheodyne, Cotati, CA, U.S.A.), a Chemcosorb 5-ODS-H column ( $150 \times 4.6 \mathrm{~mm}$ i.d., particle size $5 \mu \mathrm{m}$; Chemco Scientific Co., Osaka, Japan). The mobile phase was a mixture of a degassed solution of $20 \mathrm{~mm}$ potassium dihydrogen phosphate $(\mathrm{pH}$ adjusted to 3.7 by the addition of phosphoric acid) containing $1 \mathrm{~g} / 1$ of sodium heptane

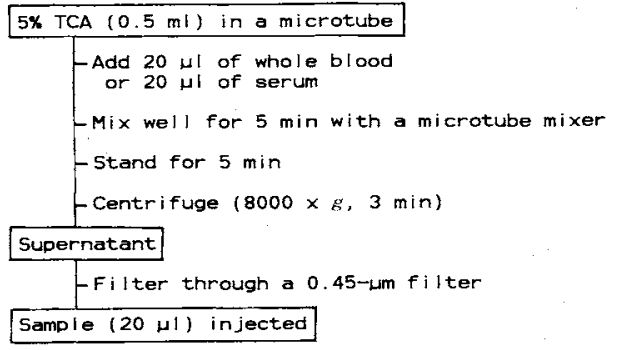

Fig. 1. Procedure for Extracting Tryptophan from Whole Blood and Serum.

$\mathrm{TCA}=$ trichloroacetic acid.

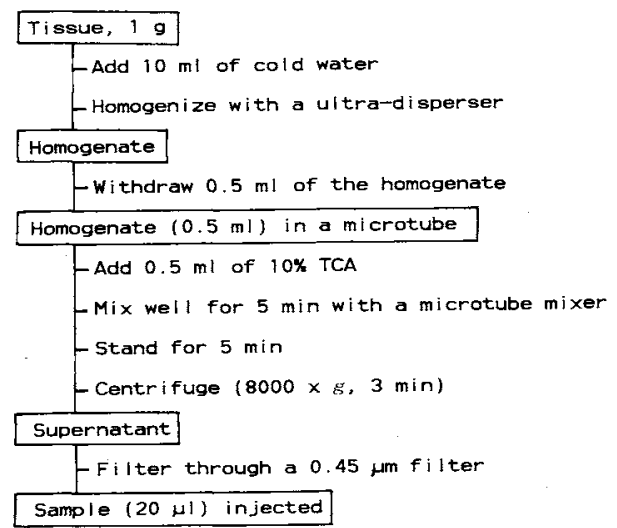

Fig. 2. Procedure for Extracting Tryptophan from Tissues.

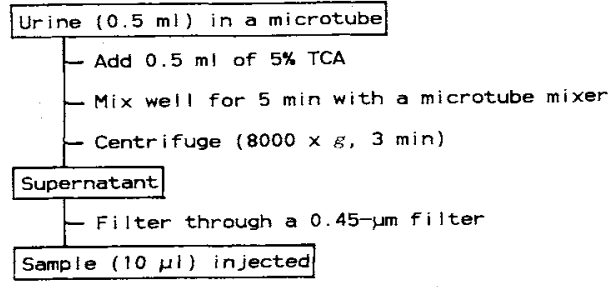

Fig. 3. Procedure for Extracting Tryptophan from Urine. sulfonate and $3 \mathrm{mg} / 1$ of EDTA-2Na-acetonitrile $(93: 7$, $\mathrm{v} / \mathrm{v}$ ) and was used at a flow rate of $1.5 \mathrm{ml} / \mathrm{min}$. The column temperature was maintained at $25^{\circ} \mathrm{C}$. Tryptophan contents in whole blood, serum, brain, and liver were electrochemically measured at $+1000 \mathrm{mV} v s$. $\mathrm{Ag} / \mathrm{AgCl}$ and tryptophan contents in urine, alkaline hydrolysates of protein, and foodstuff were fluorometrically measured at an excitation wavelength of $280 \mathrm{~nm}$ (10-nm bandpass) and at an emission

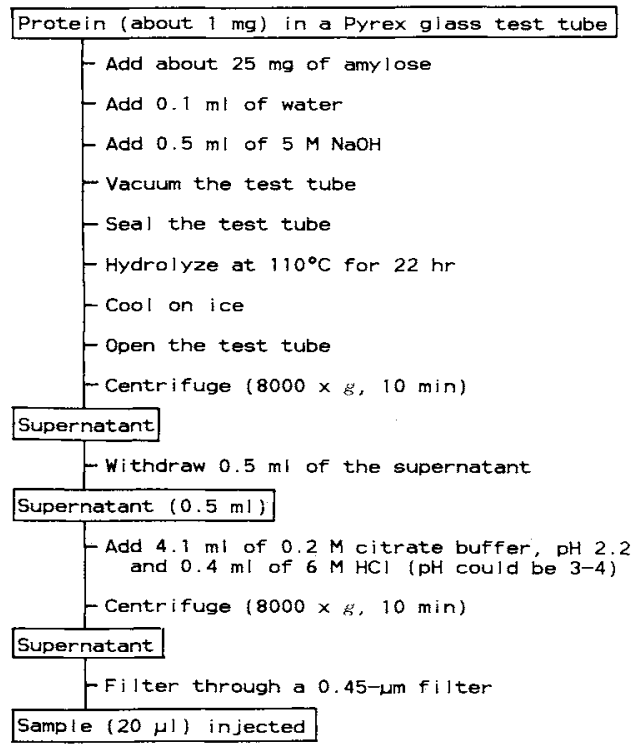

Fig. 4. Procedure for Alkaline Hydrolysis of Protein and Extracting Tryptophan from the Alkaline Hydrolysate.



Fig. 5. Procedure for Alkaline Hydrolysisof Foodstuff and Extracting Tryptophan from the Alkaline Hydrolysate. 
wavelength of $340 \mathrm{~nm}$ (10-nm bandpass). The HPLC system was interfaced with a Shimadzu Chromatopac C-R3A for data processing.

Extraction of tryptophan from biological materials and foodstuff. The procedure for extracting tryptophan from whole blood and serum in humans and rats, tissues such as liver and brain in rats, urine in humans and rats, and alkaline hydrolysate of protein such as lysozyme and albumin, and alkaline hydrolysate of foodstuff such as wheat flour are shown in Figs. 1, 2, 3, 4, and 5, respectively. The procedure for hydrolysis of protein in $\mathrm{NaOH}$ solution was based on the methods of Hugli and Moore ${ }^{16)}$ and Sato et $a .^{17)}$

\section{Results and Discussion}

\section{Detection method}

Tryptophan contents in whole blood, serum, liver, and brain were measured by electrochemical detection because the sensitivity to tryptophan was 100 times higher than by fluorometric detection, the tryptophan in each extract being eluted without interfering peaks. However, tryptophan contents in urine and an extract of alkaline hydrolysate of protein could not be detected by electrochemical detection because this tryptophan was eluted with interfering peaks. Accordingly, tryptophan contents of urine and protein were measured by the fluorometric method. The tryptophan contents in an extract of the alkaline hydrolysate of wheat flour could be measured by both detections such as electrochemical and fluorometric detections.

\section{Calibration curve and limit of detection}

The calibration curve for tryptophan was linear in the range of $0.2 \mathrm{pmol}-1000 \mathrm{pmol}$ (electrochemical detection) and $20 \mathrm{pmol}-20$ nmol (fluorometric detection) per injection. The coefficient of variation (C.V.) of the peak area of tryptophan (2 pmol per injection; five injection) was $1.6 \%$ when tryptophan was electrochemically measured and that $(200 \mathrm{pmol}$ per injection; five injection) was $1.3 \%$ when tryptophan was fluorometrically measured. The low limit of detection were $0.2 \mathrm{pmol}$ $(40.84 \mathrm{pg})$ with the electrochemical detection and $20 \mathrm{pmol}(4.08 \mathrm{ng})$ in fluorometrical method at a signal-to-noise ratio of $5: 1$.

\section{Precision and recovery of tryptophan from biological materials}

To measure the precision of the method, the measurement for tryptophan contents of samples such as whole blood, serum, liver homogenate, brain homogenate, and urine in rats (see, Table IV) were repeated five times. As shown in Table I, all the C.V. were around $2 \%$, indicating that the reproducibility of this

Table I. Precision AND ReCOVERIES OF ADDED TRYPTOPHAN (TRP) FROM WHOLE BLOOD, Serum, Liver, Brain, AND URINE IN RATS

\begin{tabular}{|c|c|c|c|}
\hline $\begin{array}{l}\text { Added } \\
\text { Trp } \\
\text { (nmol) }\end{array}$ & Found & $\begin{array}{l}\text { C.V. } \\
(\%)\end{array}$ & $\begin{array}{c}\text { Recovery } \\
(\%)\end{array}$ \\
\hline \multicolumn{4}{|c|}{ (nmol/20 $\mu$ l of whole blood) } \\
\hline 0 & $1.387 \pm 0.029$ & 2.1 & - \\
\hline $5^{* 1}$ & $6.168 \pm 0.142$ & 2.3 & $95.6 * 2$ \\
\hline \multicolumn{4}{|c|}{ (nmol/20 $\mu 1$ of serum) } \\
\hline 0 & $2.497 \pm 0.055$ & 2.2 & - \\
\hline $5 * 1$ & $7.513 \pm 0.302$ & 4.0 & $100.3^{* 3}$ \\
\hline \multicolumn{4}{|c|}{$(\mathrm{nmol} / 500 \mu \mathrm{l} \text { of liver homogenate) })^{* 4}$} \\
\hline 0 & $3.292 \pm 0.112$ & 3.4 & - \\
\hline $10^{* 5}$ & $13.159 \pm 0.276$ & 2.1 & $98.7^{* 6}$ \\
\hline \multicolumn{4}{|c|}{ (nmol/500 $\mu$ of brain homogenate) $^{* 4}$} \\
\hline 0 & $1.443 \pm 0.038$ & 2.6 & - \\
\hline $10^{* 5}$ & $11.007 \pm 0.273$ & 2.5 & $95.6 * 7$ \\
\hline \multicolumn{4}{|c|}{ (nmol/ $500 \mu \mathrm{l}$ of urine) $)^{* 8}$} \\
\hline 0 & $22.32 \pm 0.33$ & 1.5 & - \\
\hline $100 * 9$ & $122.49 \pm 2.18$ & 1.8 & $100.2 * 10$ \\
\hline
\end{tabular}

Values are means $\pm S D$ for five times.

*1 A 5- $\mu 1$ sample of $1 \mathrm{~mm}$ tryptophan was added to $20 \mu \mathrm{l}$ of whole blood or serum.

*2 $\quad(6.168-1.387) / 5 \times 100=95.6 \%$.

*3 $\quad(7.513-2.497) / 5 \times 100=100.3 \%$.

*4 Liver or brain homogenate was prepared as in Fig. 2.

*S A $10-\mu 1$ of sample of $1 \mathrm{~mm}$ tryptophan was added to $500 \mu \mathrm{l}$ of liver or brain homogenate.

*6 $\quad(13.159-3.292) / 10 \times 100=98.7 \%$.

*7 $(11.007-1.443) / 10 \times 100=95.6 \%$.

*8 Urine was diluted with $0.1 \mathrm{M} \mathrm{HCl}$ to make up to $25 \mathrm{ml}$ per day.

*9 A $10-\mu 1$ of sample of $10 \mathrm{~mm}$ tryptophan was added to $500 \mu$ l of urine.

$* 10 \quad(122.49-22.32) / 100 \times 100=100.2 \%$. 
method was very high. The test samples were prepared by adding $5 \mathrm{nmol}, 10 \mathrm{nmol}$, and $100 \mathrm{nmol}$ of tryptophan to $20 \mu \mathrm{l}$ of whole blood or serum, to $500 \mu \mathrm{l}$ of the organ tissue

Table II. Recovery of Tryptophan Present in Samples of Purified Proteins

\begin{tabular}{lccc}
\hline & $\begin{array}{c}\text { Theoretical } \\
\text { value } \\
\text { (mol/mol of } \\
\text { protein) }\end{array}$ & $\begin{array}{c}\text { Found } \\
\text { (mol/mol of } \\
\text { protein) }\end{array}$ & $\begin{array}{c}\text { Found } \\
\text { theoretical } \\
(\%)\end{array}$ \\
\hline $\begin{array}{l}\text { Lysozyme*1 } \\
\text { Albumin*2 }\end{array}$ & 6 & $5.95+0.17$ & $99.2 \pm 2.9$ \\
\hline
\end{tabular}

Values are means $\pm \mathrm{SD}$ for triplicate analyses of two hydrolysates.

*1 The concentration of lysozyme (chicken egg white) in water was calculated using $\mathrm{OD}_{28 \mathrm{~nm}}^{1 \%}=26.4$.

$* 2$ The concentration of albumin (chicken) in $0.05 \mathrm{M}$ $\mathrm{NaOH}$ was calculated using $\mathrm{OD}_{280 \mathrm{~nm}}^{1 \%}=7.5$. homogenate, and to $500 \mu 1$ of urine respectively, according to procedures shown in Figs. 1, 2, and 3. High recoveries of tryptophan from these samples were obtained (Table I).

Recovery of tryptophan present in protein The recovery of tryptophan contents in

Table IH. Stability of Tryptophan in a Trichloroacetic ACID Extracts of BIological Materials in Rats

\begin{tabular}{lrrrr}
\hline & $0 \mathrm{hr}$ & $24 \mathrm{hr}$ & $48 \mathrm{hr}$ & $72 \mathrm{hr}$ \\
\hline Whole blood & 100 & 102.7 & 101.5 & 102.7 \\
Serum & 100 & 98.7 & 100.1 & 100.1 \\
Liver & 100 & 100.6 & 104.9 & 103.3 \\
Brain & 100 & 100.9 & 99.1 & 104.0 \\
Urine & 100 & 101.9 & 100.7 & 103.5 \\
\hline
\end{tabular}

Values are an average of two samples.

The extracts of trichloroacetic acid were kept at $0-4^{\circ} \mathrm{C}$.
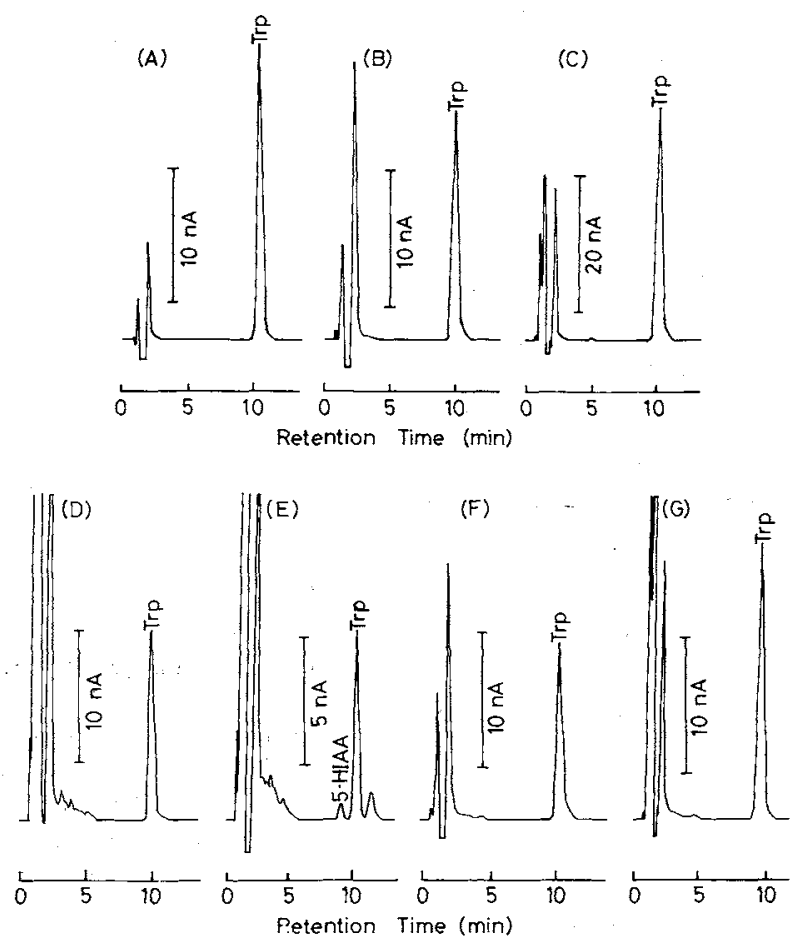

Fig. 6. Chromatograms (Electrochemical Detection) of (A) Standard Tryptophan in 5\% Trichloroacetic Acid ( $100 \mathrm{pmol} / 10 \mu \mathrm{l}$ injected), (B) an Extract of Rat Whole Blood (sample size was $20 \mu$ l containing $76.0 \mathrm{pmol}$ of tryptophan), (C) an Extract of Rat Serum (sample size was $20 \mu$ l containing 158.7 pmol of tryptophan), (D) an Extract of Rat Liver (sample size was $20 \mu$ containing 63.5 pmol of tryptophan), (E) an Extract of Rat Brain (sample size was $20 \mu \mathrm{l}$ containing $31.5 \mathrm{pmol}$ of tryptophan); 5-HIAA = 5-hydroxyindole-3-acetic acid, (F) an Extract of Human Whole Blood (sample size was $20 \mu$ containing 57.1 pmol of tryptophan), and (G) an Extract of Human Serum (sample size was $20 \mu 1$ containing 92.7 pmol of tryptophan). 
samples of purified proteins were observed to be $99.2 \pm 2.9 \%$ for lysozyme (triplicate analysis of two hydrolysates) and $98.5 \pm 1.6 \%$ for albumin (triplicate analysis of two hydrolysates) as shown in Table II. These results indicated that the procedure for the alkaline hydrolysis used (Fig. 4) is suitable for measuring tryptophan in protein as reported by Hugli and Moore ${ }^{16)}$ and Sato et al. ${ }^{17)}$

\section{Stability of tryptophan in a trichloroacetic acid extract of biological materials}

Since tryptophan is known to be labile in an acid solution, the stability of tryptophan in the trichloroacetic acid extracts of whole blood, serum, liver, brain, and urine was examined. As shown in Table III, the tryptophan in the acid extracts from whole blood, serum, liver, brain, and urine was stable within $72 \mathrm{hr}$ when the samples were stored at $0-4^{\circ} \mathrm{C}$. Geeraerts et al. ${ }^{18)}$ reported that tryptophan and its metabolites such as kynurenine, serotonin, 5-hydroxytryptophan, 5-hydroxyindole-3-acetic acid, and kynurenine acid in urine were stable within 7 days when the urine was stored at $4^{\circ} \mathrm{C}$ and the $\mathrm{pH}$ was adjusted to 2 . Sato et al. ${ }^{17)}$ reported that the tryptophan in a hydrolysate of lysozyme was stable at least for 14 days when the hydrolysate was stored at $5^{\circ} \mathrm{C}$ and the $\mathrm{pH}$ was adjusted to 4.2 . In the present experiment, the tryptophans in alkaline hydrolysates of lysozyme, albumin, and wheat flour were stable at least for 7 days when the alkaline hydrolysates was prepared according to the procedure as shown in Figs. 4 and 5 , and stored at $0-4^{\circ} \mathrm{C}$.

\section{Application of the method}

Electrochemical detection. The chromatogram of the standard tryptophan is shown in Fig. 6-A, tryptophan being eluted at about $10.5 \mathrm{~min}$. The chromatograms of the extracts of rat whole blood, rat serum, rat liver, rat brain, human whole blood, and human serum are shown in Fig. 6-B, -C, -D, -E, -F, and -G, respectively. Tryptophans in these samples were characterized on the basis of these retention time, the total HPLC analysis being
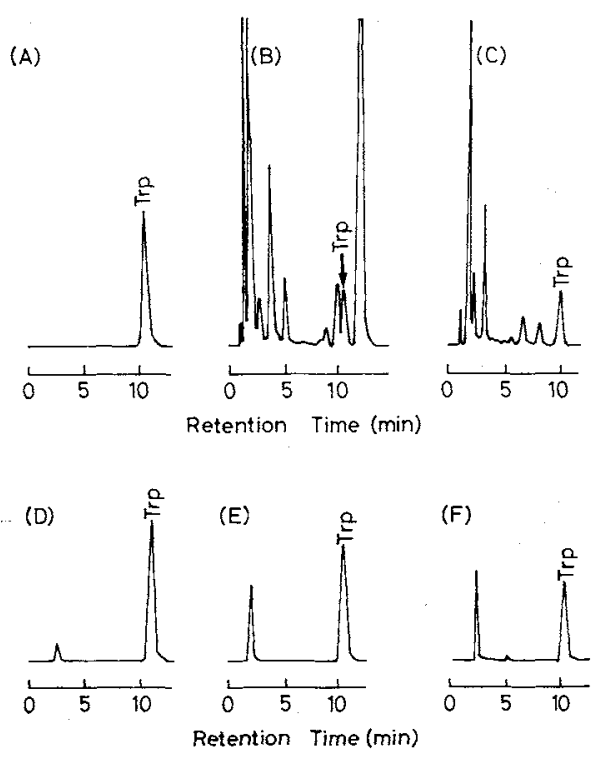

Fig. 7. Chromatograms (Fluorometric Detection) of (A) Standard Tryptophan in $5 \%$ Trichloroacetic Acid (500 pmol $/ 10 \mu 1$ injected; Shimadzu Chromatopac C-R3A, attenuation 4), (B) an Extract of Rat Urine (sample size was $10 \mu$ l containing 171 pmol of tryptophan; attenuation 4), (C) an Extract of Human Urine (sample size was $10 \mu 1$ containing 463 pmol of tryptophan; attenuation 5), (D) an Extract of Alkaline Hydrolysate of Lysozyme (sample size was $20 \mu$ containing 1186 pmol of tryptophan; attenuation 5), (E) an Extract of Alkaline Hydrolysate of Albumin (sample size was $20 \mu 1$ containing 506 pmol of tryptophan; attenuation 4), and (F) an Extract of Alkaline Hydrolysate of Wheat Flour (sample size was $20 \mu$ l containing $341 \mathrm{pmol}$ of tryptophan; attenuation 4).

about $12 \mathrm{~min}$. When sodium heptane sulfonate was omitted from the mobile phase, tryptophan was eluted at about $3.5 \mathrm{~min}$ with interfering peaks.

Fluorometric detection. The chromatogram of the standard tryptophan is shown in Fig. 7-A. The chromatograms of the extract of rat urine, human urine, alkaline hydrolysate of lysozyme, alkaline hydrolysate of albumin, and alkaline hydrolysate of wheat flour samples are shown in Fig. 7-B, -C, -D, -E, and -F, respectively. Tryptophans in these samples were characterized on the basis of these retention time and the entire excitation and emission spectra between $250 \mathrm{~nm}$ and $400 \mathrm{~nm}$.

Tryptophan contents of whole blood, serum, liver, brain, and urine in rats fed with a $20 \%$ 
Table IV. Tryptophan Contents in Biological Materials and FoodstufF

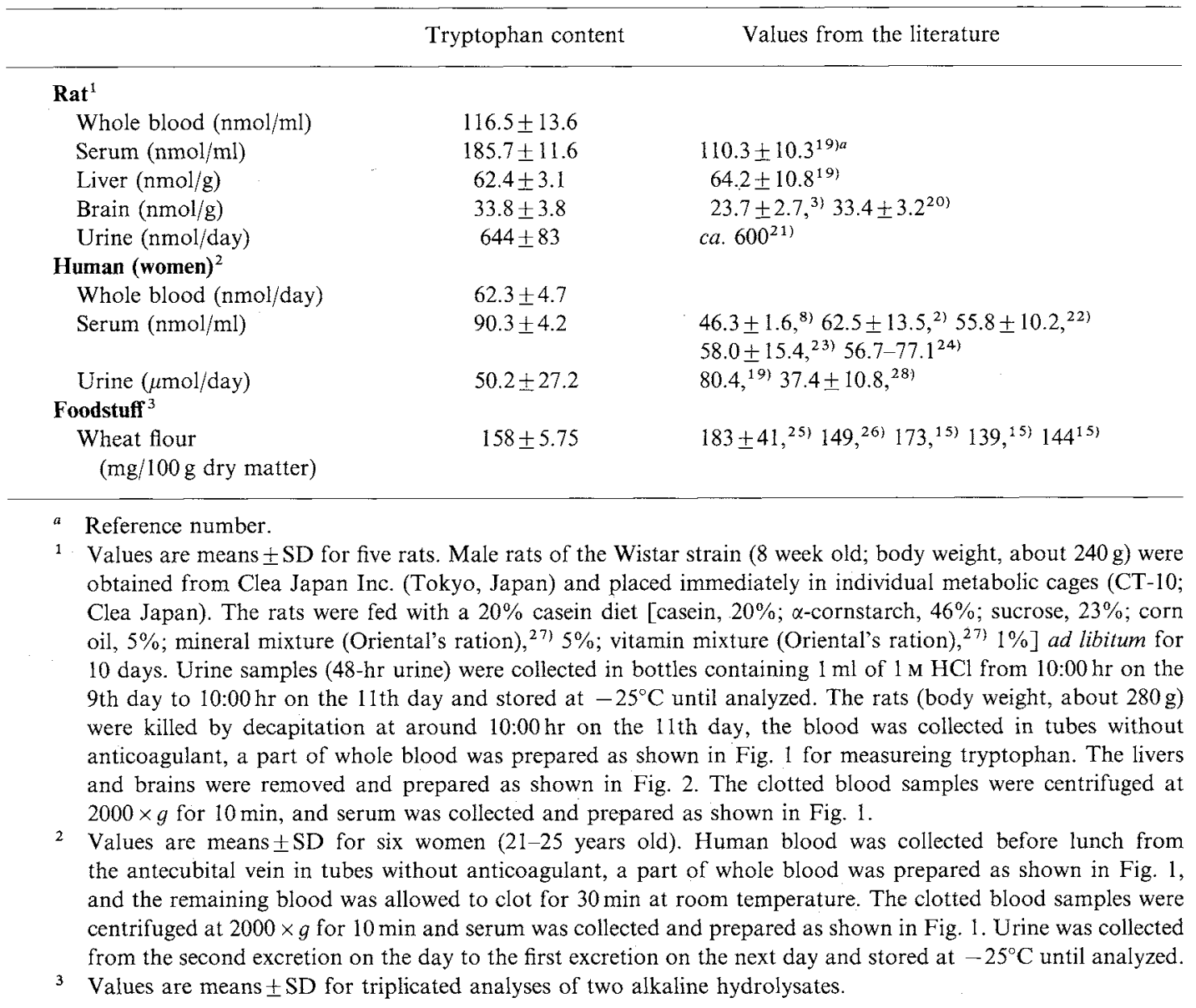

casein diet, and whole blood, serum, and urine in human, and wheat flour are given in Table IV.

Under the HPLC conditions used in this study, the tryptophan metabolites such as xanthurenic acid (about $1.5 \mathrm{~min}$ ), 3-hydroxykynurenine $(2.1 \mathrm{~min})$, kynurenic acid $(2.5$ min; detected with an excitation wavelength of $344 \mathrm{~nm}$ and an emission wavelength of $398 \mathrm{~nm}$ : did not react electrochemically and no detectable peak at an excitation wavelength of $280 \mathrm{~nm}$ and an emission wavelength of $34.0 \mathrm{~nm}$ ), 5-hydroxytryptophan (3.2 $\mathrm{min})$, kynurenine (4.5 min), 3-hydroxyanthranilic acid (5.2 min), 5-hydroxyindole-3-acetic acid $(9.5 \mathrm{~min})$, anthranilic acid (16 $\mathrm{min}$ ), serotonin ( $34 \mathrm{~min}$ ), and indole-3-acetic acid $(60 \mathrm{~min})$ were eluted, but tryptamine was not eluted. So, these trypto- phan metabolites did not disturb the detection of tryptophan, and these metabolites except for 5-hydroxyindole-3-acetic acid (1972 \pm 286 $\mathrm{pmol} / \mathrm{g}$ brain; mean $\pm \mathrm{SD}$ for five rats) in brain were not below the limits of detection under these preparation methods.

\section{References}

1) M. Ghebregzabher, S. Rufini, M. G. Castellucci and M. Lato, J. Chromatogr., 222, 191 (1981).

2) I. Morita, M. Kawamoto, M. Hattori, K. Eguchi, K. Sekiba and J. Yoshida, J. Chromatogr., 526, 367 (1990).

3) J. Wagner, P. Vitali, M. G. Palfreyman, M. Zaraika and S. Huot, J. Neurochem., 38, 1241 (1982).

4) J. P. M. Wielderd and C. J. K. Mink, J. Chromatogr., 310, 379 (1984).

5) Y. Sagara, Y. Okatani, S. Yamanaka and T. Kiriyama, J. Chromatogr., 431, 170 (1988). 
6) M. Peat and J. Gibb, Anal. Biochem., 128, 275 (1983).

7) J. Yamada, Y. Sugimoto and K. Horisaka, Anal. Biochem., 129, 460 (1983).

8) A. M. Krstulovic, P. R. Brown, D. M. Rosie and P. B. Champlin, Clin. Chem., 23, 1984 (1977).

9) A. M. Krstulovic, M. J. Friedman, P. R. Sinclair and J. Felice, Clin. Chem., 27, 1291 (1981).

10) G. A. Anderson, J. G. Young, D. J. Cohen, K. R. Schlicht and N. Patel, Clin. Chem., 27, 775 (1981).

11) A. M. Krstulovic, M. J. Friedman, H. Colin, G. Guiochon, M. Gaspar and K. A. Pajer, $J$. Chromatogr., 297, 271 (1984).

12) I. Morita, T. Masujima, H. Yoshida and H. Imai, Anal. Biochem., 151, 358 (1985).

13) J. D. Jong, U. R. Tjaden and W. V. Hof, J. Chromatogr., 282, 443 (1983).

14) S. Delhaye and J. Landry, Anal. Biochem., 159, 175 (1986).

15) S. R. Hagen and J. Augustin, J. Micronutr. Anal., 5, 303 (1989).

16) T. E. Hugli and S. Moore, J. Biol. Chem., 247, 2828 (1972).

17) H. Sato, T. Seino, T. Kobayashi, A. Murai and Y. Yugari, Agric. Biol. Chem., 48, 2961 (1984).
18) F. Geeraerts, L. Schimpfessel and R. Crokart, Clin. Chim. Acta, 102, 247 (1980).

19) W. D. Denckla and H. K. Dewey, J. Lab. Clin. Med., 69, $160(1967)$.

20) J. D. Fernstrom, M. J. Hirsch, B. K. Madras and L. Sudarsky, J. Nutr., 105, 1359 (1975).

21) K. Shibata, K. Motooka, K. Murata and K. Iwai, J. Nutr. Sci. Vitaminol., 26, 571 (1980).

22) Y. Hijikata, K. Hara, Y. Shiozaki, K. Murata and Y. Sameshima, J. Clin. Chem. Clin. Biochem., 22, 291 (1984).

23) E. F. Marshall, W. N. Kennedy and O. Eccleston, Biochem. Med. Metab. Biol., 37, 81 (1987).

24) S. Inoue, T. Tokuyama and K. Takai, Anal. Biochem., 132, 468 (1983).

25) G. Sarwar, D. A. Christensen, A. J. Finlayson, M. Friedman, L. R. Hackler, S. L. McKenzie, P. L. Pelett and R. Tkachuk, J. Food Sci., 48, 526 (1983).

26) J. Landry, S. Delhaye and G. Viroben, J. Agric. Food Chem., 36, 51 (1988).

27) K. Shibata and H. Matsuo, J. Nutr., 119,896(1989).

28) A. R. Green, J. K. Aronson, G. Curzon and H. F. Woods, Br. J. Clin. Pharmac., 10, 603 (1980). 